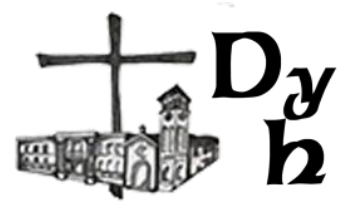

La libertad del docente católico: el desafío en la escuela del siglo XXI

Lic. María Ayelén Díaz Lapérgola

Dios y el hombre, vol. 4, n. 1, e054, 2020

ISSN 2618-2858 - https://doi.org/10.24215/26182858e054

https://revistas.unlp.edu.ar/DyH/index Cátedra libre de pensamiento cristiano - UNLP

Seminario Mayor San José

La Plata, Buenos Aires, Argentina

\title{
LA LIBERTAD DEL DOCENTE CATÓLICO: EL DESAFÍO EN LA ESCUELA DEL SIGLO XXI
}

\author{
Catholic Teacher Freedom: \\ A Challenge in the School of the 21st Century \\ Lic. María Ayelén Díaz Lapérgola \\ ayelen.pilar06@gmail.com \\ Investigadora independiente - La Plata - Argentina
}

\section{Resumen}

La realidad escolar, en la que a diario desempeña su tarea el docente católico, reviste una singular responsabilidad personal, profesional y vocacional. Esto conlleva a hacer una lectura discriminada de los desafíos que se presentan en el aula y a los que el docente debe atender, mediando entre la normativa oficial, el sentido común y las convicciones personales de fe que revisten a su creencia.

Sin embargo, cuenta con una brújula existencial que es la vida de Dios hecho hombre, manifiesto en su llamado personal al ejercicio de la docencia y a la búsqueda consecutiva de instaurar en el aula el Reino de los cielos y los fines de los bienes eternos.

Palabras clave: actualidad escolar, vocación, libertad del profesor católico

\section{Abstract}

School reality, where Catholic teachers are immersed, demands a singular personal, professional and vocational responsibility. Leading, thus, to take a deep look into the challenges that these teachers face inside their classrooms, urging them to take action balancing official norms, common sense and their own personal beliefs and convictions.

Nevertheless, Catholic teachers rely on an existential compass which is the life of God made man, inherent in their personal calling and their endless pursuit to establish the Kingdom of God inside their classroom.

Key words: school reality, vocation, catholic teacher freedom 
En memoria y agradecimiento a cada uno de los que han dejado huellas imborrables en mi vocación docente; muy especialmente, a mi gran tutor y maestro, Monseñor Raul Gross, llamado a gozar de la gracia celestial después de haber vivido fielmente la libertad del docente católico al modo del Divino Maestro.

\section{La libertad del docente católico: el desafío en la escuela del siglo XXI}

La variedad de situaciones en la que los docentes en general, y los católicos en particular, a diario enfrentamos es una notoria diversidad de inconvenientes; debemos atender e intentar dar solución en el espacio del aula actual a realidades que, no en todos los casos, tienen origen en la escuela. Muchas de ellas suponen cambios de paradigmas sociales y epocales, que promueven la modificación en la conducta humana y repercuten, no sólo en la posibilidad de aprendizaje de los alumnos a nivel cognitivo, sino, también, en cuanto a hábitos y conductas morales.

El mayor dilema está en elegir el modo de actuar: de acuerdo a las indicaciones legisladas positivamente, según el sentido común propio o considerando los principios de moralidad que portamos.

El docente católico, como parte de la causa eficiente de la educación, desarrolla la actividad propia en un contexto epocal, que da a su tarea un carácter peculiar y enmarca en ella sus posibilidades de producir lo esperado. A diario hemos de leer los signos de los tiempos, observando la novedad que imponen en forma directa en el trabajo educativo, fortaleciendo $u$ obstaculizando sus metas y fines.

La tarea del docente cristiano debe tender a la búsqueda de la libertad que obtenemos en Cristo y a la que hemos sido llamados a realizar. Como testigo en el tiempo de la postmodernidad y en el ámbito educativo, la tarea docente se encuadra en la búsqueda de la sabiduría en el camino de la Verdad. Es así como la autoconciencia y conciencia ponen al hombre en general y al docente en particular en cuadro de situación para la toma de decisiones responsables y orientadas al bien. Nos convertimos en dueños del hacer, de nuestra vida asumida como un bien personal. Y como tal, su tarea influye de manera directa en la educación de la libertad y para la libertad, la cual presupone un sano optimismo y confianza en la bondad de la persona y en la sensatez de los grupos en la proposición de valores y el camino a la madurez. 


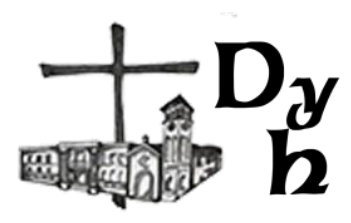

La moral cristiana es una moral libre que tiene como fundamento el bien. Jesús, en el Evangelio según San Juan, dijo: "Les aseguro que todo el que peca es esclavo del pecado" (Jn 8, 34) ${ }^{1}$. Por lo que el obrar ético cristiano, y en particular del docente católico, se asienta en el centro de la libertad moral porque su anhelo es la aspiración a la felicidad, y comprende que no existe felicidad sin amor y viceversa. Es entonces que el docente católico debe asumir la libertad tal como la define el apóstol San Pablo, "la liberación de la esclavitud del pecado, de la muerte y del yugo de la antigua ley para lanzarnos al dinamismo del amor" (cf. Rm 6, 11. 18. 22; 8, 2).

\section{Aproximación a la situación escolar actual}

Como suele decirse, la historia se ha acelerado y los cambios mismos se vuelven vertiginosos, ya que se comunican con gran velocidad a todos los rincones del planeta. A diferencia de otras épocas, la novedad de estos cambios tiene alcance global, $y$, como tal, traen consecuencias en ámbitos de la vida social, la cultura, la economía, la política, las ciencias, el deporte, las artes, la religión y la educación. $Y$ en esta última se hacen foco todos los anteriores siendo evidentes en el micro espacio social del aula.

Las nuevas reformas educativas que se han dado en nuestro continente, pero particularmente en nuestro país, aparecen centradas únicamente en el desarrollo de conocimientos y habilidades, ya que conciben la educación preponderantemente en función de la producción, la competitividad y el mercado. Sin embargo, al centrar la mirada en un único aspecto constitutivo del hombre, produce un reduccionismo antropológico, sin promover el despliegue de los mejores valores de los jóvenes ni su espíritu religioso. Tampoco se detiene en la educación de la afectividad y la emotividad como medios para promover el acercamiento de los educandos al concepto y experiencia de la felicidad. A un lado queda la vida virtuosa, entendida como un concepto erróneo y caduco propio de una vida ortodoxa y cerrada.

La función del docente se reduce a ser meros sujetos intelectuales transformadores que desarrollan pedagogías contra hegemónicas. Tanto el docente como los alumnos deben, en el espacio del aula, educarse para luchar

\footnotetext{
${ }^{1}$ Citamos por la edición de la Biblia "El libro del Pueblo de Dios" de A. J. Levoratti y A. B. Trusso
} 
contra las diversas formas de opresión oculta y vigente en la sociedad. Quedan, así, en evidencia en todos los documentos oficiales, tanto más en los lineamientos curriculares, las bases ideológicas con las que están construidos los cimientos del sistema educativo actual: "Los múltiples desafíos que enfrenta la educación en la actualidad, podrán ser debidamente interpelados a través de una formación que priorice la de-construcción de los entramados que enmascaran la realidad, develando los mecanismos de poder y la génesis del sentido común ocultador de la misma. Para cumplir tal cometido, el Sistema Educativo Provincial debe garantizar la formación de docentes convencidos del potencial liberador y transformador de las situaciones de injusticia que toda pedagogía crítica conlleva" (Marco General de la Formación docente de Nivel Inicial y EPB de la Provincia de Buenos Aires, 2007).

En este sentido es que ha llegado al aula la herramienta del cuestionamiento constante a todo aquello que revista algún tipo de estructura: instituciones, normativas, principios, religión, entre otros, relativizando absolutamente todo, llegando así incluso a la desnaturalización más extrema de la realidad.

De este modo, las instituciones que ahogan los deseos, los sueños y expectativas de las personas deben ser descontruidas, puestas en evidencia por su naturaleza represiva y ser reemplazadas por sistemas de relaciones interpersonales dialógicos y fluidos. Cuestionándolas se rechaza, en forma explícita o implícita, la autoridad que emana de ellas y los mecanismos de conducción implementados. Porque, en este marco, toda autoridad es represiva por definición, y no se puede ejercer ninguna forma de conducción si no es procurando el consenso entre sus miembros.

Una de las instituciones que sufrió y sufre en la actualidad este cambio de valores es la escuela. Los rasgos centrales que han dado por años vigencia, valor, confianza y compromiso de y a la escuela, como consecuencia de lo anterior, se han perdido, devaluados, cuestionados y alejados del proyecto vital de muchos de los miembros que la conforman.

En el mismo dilema de la escuela se encuentra la validación de autoridad de los docentes que en ella desempeñan su actividad profesional. Al respecto afirma Tenti Fanfani: "en la actualidad el docente se construye su propia autoridad, luchando cada día para lograrla y mantenerla" (Tenti Fanfani, 2004). 


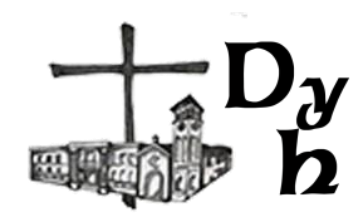

En las escuelas de confesión católica, enseñar religión por momentos pareciera tornarse un inconveniente imposible de afrontar. Para desarrollar este punto es oportuno tomar y analizar brevemente las palabras del poeta Gabriel Celaya sobre el sentido de la educación:

Educar es lo mismo

que poner motor a una barca

hay que medir, pesar, equilibrar...

... y poner todo en marcha

Pero para eso

uno tiene que llevar en el alma

un poco de marino...

un poco de pirata...

un poco de poeta...

y kilo y medio de paciencia concentrada.

\author{
Pero es consolador soñar, \\ mientras uno trabaja, \\ que ese barco, ese niño \\ irá muy lejos por el agua; \\ soñar que ese navío \\ llevará nuestra carga de palabras \\ hacia puertos distantes, hacia islas lejanas, \\ soñar que, cuando un día \\ esté durmiendo nuestra propia barca, \\ en barcos nuevos seguirá nuestra bandera enarbolada.
}

El docente católico, particularmente el profesor de religión, tiene algo de marino, algo de pirata, algo de poeta y algo de paciente. Los docentes de las áreas de la enseñanza religiosa escolar habitualmente observamos como problemáticas la irreligión, la resistencia para ver los designios de Dios en la 
vida social, el juzgamiento por parte de los alumnos al recibir principios de carácter religioso y moral en otros espacios que no sea el de la Formación Religiosa; el problema de las ideologías dominantes en el mundo actual liberalismo, marxismo, secularismo, relativismo, etc.-, las herejías contemporáneas. Son solo algunos del amplio abanico de situaciones conflictivas en torno a cuestiones religiosas.

Es lógico pensar que, en una sociedad donde creer da lo mismo y hasta es considerado de retrógrados y molestos, el docente católico es un extraño individuo hablando en un lenguaje totalmente distinto y fuera de lo ordinario, si consideramos la oposición ideológica de base que en el aula actual impera.

Algunos jóvenes se encuentran subsumidos en un mundo unidimensional, en el que sólo cuenta lo que es útil y, sobre todo, lo que ofrece resultados prácticos y técnicos. Para ellos hablar de religión o de Dios es inconcebible porque estos últimos no son medibles en ninguna de las categorías anteriores.

También es de considerar uno de los grandes factores evidentes en el aula: alejamiento de la fe de muchos jóvenes. El fenómeno comienza frecuentemente por el gradual abandono de la práctica religiosa, con el tiempo se convierte en una hostilidad hacia las instituciones eclesiásticas y una crisis de aceptación de la fe y de los valores morales a ella vinculados. El alejamiento toma, con frecuencia sistemática, aspecto de total indiferencia religiosa. Algunos de los expertos sostienen que ciertos comportamientos juveniles pueden interpretarse como sustitutivos para rellenar el vacío religioso a través del culto pagano al cuerpo, evasión en la droga, los múltiples y variados ritos de masas que hasta pueden producir fanatismo o de alienación en los niños y jóvenes que habitan las aulas en la actualidad.

La ignorancia religiosa, la ausencia de familias o, de estar presentes, falta de educación en la fe, la difusión de comportamientos neopaganos, la necesidad de una preparación intelectual de la fe y la actualización permanente del personal docente despierta en los docentes católicos una de sus grandes y desafiantes inquietudes profesionales. 


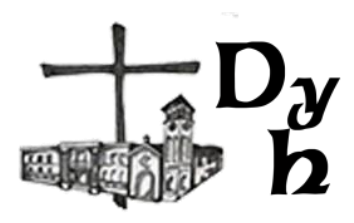

En las aulas de nuestras escuelas, hoy convive el hombre gnóstico - poseedor del saber pero falto de unidad, que además necesita de lo esotéricocon el indiferentista religioso -refiere al hombre que se mueve como oveja sin pastor, subsumida en una confusión abrumadora-. Y además aquel alumno que, sin más dudas que las que atraviesa todo aquel que pasa por algún tipo de crisis, sigue aferrándose a aquella Verdad única que le transmite paz, lo fortalece y lo consuela.

Sin embargo, existen también variedad de buenos síntomas y muchos de ellos muy prometedores. Hay también jóvenes ejemplares por su comportamiento religioso, moral y escolar, que en la mayoría de los casos poseen un óptimo ambiente familiar ayudado por la comunidad eclesial y por la misma escuela. Los hay, también, jóvenes que buscando una religiosidad más consciente, se preguntan por el sentido de la vida y encuentran en el Evangelio la respuesta a sus inquietudes. Otros, superando las crisis de indiferencia y duda, se acercan o retornan a la vida cristiana.

Este es el crisol de realidades que enfrenta el problema de la fe, expuesto en la más extrema expresión dentro del espacio del aula. Tal como lo define el, por entonces, Cardenal Bergoglio, en esta "góndola del supermercado religioso" (Bergoglio, 2006) es donde debe desenvolver la tarea educativa-evangelizadora el docente católico.

No olvidemos que en la escuela confesional católica la educación de la fe busca como fin el crecimiento personal y la maduración cristiana. Todo ese empeño formativo requiere discernimiento, adecuación a la experiencia cultural y al momento evolutivo de las personas.

Por otra parte, considerando que "corresponde a la escuela cultivar con asiduo cuidado las facultades intelectuales, creativas y estéticas del hombre, desarrollar rectamente la capacidad de juicio, la voluntad y la afectividad, promover el sentido de los valores, favorecer las actitudes justas y los comportamientos adecuados, introducir en el patrimonio cultural conquistado por las generaciones anteriores, preparar para la vida profesional y fomentar el trato amistoso entre los alumnos de diversa índole y condición, induciéndolos a comprenderse mutuamente" (Sagrada Congregación para la Educación Católica, 1982), el docente laico católico también debe desarrollar sus tareas profesionales tanto en escuelas de gestión privada como estatal. 
En ambos casos, sobre todo en los que hablamos de escuelas no confesionales, pueden estar orientadas en un proyecto educativo con una determinada concepción del hombre y de la vida o por una determinada ideología, o admitir, dentro de un marco de principios bastante generales, la coexistencia de diversas concepciones ideológicas entre los educadores. Esta pluralidad manifiesta entiende dicha coexistencia como un espacio propicio para que el docente laico católico muestre la presencia de Cristo y de su Iglesia.

El fin es que, no sólo por los contenidos, sino también por las acciones y las palabras del docente, el alumno pueda descubrir los auténticos valores humanos. Lo cual deberá estar enmarcado en un profundo respeto hacia las convicciones de todos, siempre que no vayan en contra de los derechos humanos más profundos.

Sin embargo, como desprendimiento del análisis anterior, la tarea en la escuela del docente católico es la de afrontar en el aula los temas instalados en el colectivo social por el "prime time" de los medios de comunicación masiva.

La importancia creciente del entorno y de las medios de comunicación social, con sus contradictorias $y$, a veces, nocivas influencias, sumado a la consiguiente incapacidad progresiva de la familia para afrontar por sí sola todos esos graves problemas y exigencias, hace cada vez más necesaria la intervención de la escuela en la mediación y clarificación de estos debates.

En torno a esto, los docentes descubrimos en los alumnos serias dificultades en la comprensión, dificultad para expresar sus ideas de forma oral y escrita. Entre los factores que manifiestan como promotores de estos inconvenientes se encuentra el uso del celular y otros dispositivos móviles en forma permanente. Todo esto es causa y fin para dificultar al desarrollo del espíritu crítico frente a estos avasallamientos informativos.

A su vez, algunos pensadores contemporáneos sostienen que la realidad actual trae aparejada una crisis de sentido, entendida como la herramienta que da unidad a todo lo que existe y sucede en la experiencia; la que se pone a disposición del hombre a través de nuevas tradiciones culturales que representan la hipótesis de realidad con la que cada ser humano puede mirar el mundo en que vive. Vuelven, entonces, a jugar un papel preponderante los 


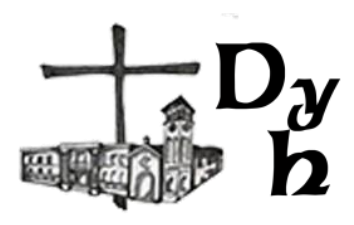

medios de comunicación que, presentando nuevas imágenes más atractivas y fantasiosas, incluso siendo el hombre consciente de ello, en muchas circunstancias solo ofician como distracción del sentido importante de la vida.

La falta de herramientas para el procesamiento de la información sólo se subsana con más información, retroalimentando la ansiedad de quien percibe que está en un mundo opaco no comprensible.

Esta realidad llevada al aula ha producido la necesidad de entender e incorporar su uso como medios y herramientas propicios para el aprendizaje. El problema educativo postmoderno se basa en que aun "tenemos escuelas del siglo XIX, con docentes del siglo XX y alumnos del siglo XXI".

Parafraseando a la psicopedagoga Mariela Cordero, las escuelas en la actualidad van trabajando lentamente tras las necesidades del momento para la vertiginosidad epocal con la que convive. Si bien ese concepto hace referencia a qué enseñamos actualmente en la escuela, podría utilizarse para preguntarnos cómo lo hacemos y si contamos no solo con las herramientas adecuadas sino, también, con la capacitación correspondiente para llevarlo a cabo. Es justa la descripción que hace el psicólogo sanjuanino Lucas Malaisi afirmando que "la tecnología va en avión, mientras que la escuela intenta seguirla a pie" (Malaisi, 2016).

Frente a la aparición de los avances tecnológicos, de información y de entretenimiento, la variación cognitiva, conductual y de comportamiento que ello ha generado y sus múltiples efectos, para el catedrático Nick Bostrom "estamos educando a toda una generación en este contexto totalmente nuevo... sin ninguna evidencia sólida de lo que ocurrirá después" (Woods, 2006).

Es tan común la interconexión permanente, que ya algunos investigadores se preguntan si no se estará conformando un cerebro humano diferente al hasta ahora conocido; con nuevas conexiones preparadas para responder a estímulos en forma más rápida y observando que es cada vez más alta la imposibilidad de la capacidad de retener información. Por el contrario, otros creen que el hombre se ha adaptado a una nueva ampliación cognitiva con mayor determinación en lo visual, no tanto en lo verbal. 
La radio, la televisión, el diario, las redes sociales y los portales de internet conforman un entramado cargado de información de muy variada índole. Una tarea difícil de abordar, producto del aturdimiento que provocan, para la selección de información, el recorte de la opinión, comparación de datos y elaboración de juicios personales, con argumentaciones válidas para el debate y la discusión. El docente a diario se encuentra atendiendo la agenda informativa instalada por estos medios que producen intriga, curiosidad $y$, en el peor de los casos, adoctrinamiento de los alumnos para la repetición inalterable del discurso mediático de turno.

Por otra parte se encuentran los grupos comunicacionales como las redes sociales, los amigos y compañeros, como también el ambiente social y cotidiano. Los conflictos entre pares más habituales encuentran su origen o se consolidan en las redes sociales de participación interpersonal. Estas últimas son una parte significativa de la identidad y del estilo de vida de los jóvenes. Su mayor incidencia se hace evidente cuando lleva a ciertos vicios, manifiesto en peligros como el aislamiento, la pereza, la desolación y el aburrimiento. También problemas como la pornografía, el ciberbullying y el sexting, han distorsionado la percepción de los jóvenes post-modernos sobre la sexualidad humana, e incluso respecto del concepto de lo público y lo privado.

Las nuevas tecnologías no sólo forman parte de las exigencias explícitas de los lineamientos curriculares vigentes, sino que además han favorecido a la discusión y la posterior habilitación del uso de dispositivos móviles adentro del aula con fines pedagógicos. Es decir, teléfonos móviles, i-pads, notebooks y iphones se constituyen en la actualidad como una herramienta más en el desarrollo pedagógico de la educación.

El problema sucinto, a consecuencia de esta nueva incorporación son los comentarios permanentes e inadecuados por los chats, escraches entre pares por videos o fotos en las redes -favorecedores de la mayoría de los casos de Bullying-, lo mismo que para con los docentes. Por tal motivo el uso de estos dispositivos en las aulas de la provincia de Buenos Aires tuvo que ser reglamentado por la Resolución 1728/06, que fue derogada en 2016 por el Ministro de Educación de la Provincia de Buenos Aires, Dr. Alejandro Finocchiaro, con la resolución 778. 


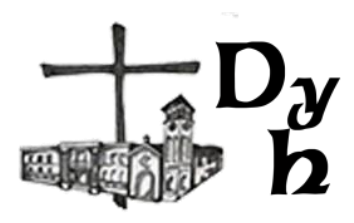

Por otra parte, se suman los serios problemas convivenciales: falta de tolerancia y respeto por el otro, juzgamientos hostiles, entre otros.

Respecto a ellos, también la Dirección General de Cultura y Educación de la Provincia de Buenos Aires en el año 2012 ha presentado la Comunicación Conjunta $N^{\circ} 1$, conocida como la Guía de Orientación para la Intervención en Situaciones Conflictivas en el Escenario Escolar o vulgarmente conocido como el Protocolo de Acción en Situaciones de Conflicto. En ella se detallan una serie de conflictos internos y externos al espacio del aula, pero que repercuten en su funcionamiento habitual y demandan una especial atención siguiendo las indicaciones allí prescriptas.

Otros de los problemas que se hacen presentes en el espacio del aula es el de la familia. Si bien no es un agente que actúa en forma directa en el ambiente del aula, su presencia, su conformación, la dedicación en la formación de valores, hábitos de comportamientos personales y sociales dan el presente a diario en cada una de las actividades escolares.

En la modernidad, se incorporaba en la dinámica familia-escuela el estímulo de los niños y jóvenes al conocimiento indispensable de aprendizajes como futuros ciudadanos y trabajadores. En este contexto, los roles se encontraban bien definidos y no se prestaba a confusión la intervención de cada una en su espacio; cada institución confiaba en la acción coherente de la otra y no se involucraba en el otro campo. En definitiva, se concluye que, ni la familia concebía a la escuela como fuente de descontento, ni la escuela requería de los padres porque contaba en forma implícita con su aval.

A fines del siglo $X X$ esta dualidad ha sufrido un desmoronamiento profundo sobre las formas y miradas de abordaje de la conflictividad, en el que incluso se ha visto afectado el concepto de familia. Los docentes denuncian no sólo la gran ausencia de los padres en el acompañamiento y apoyo escolar, sino también la escasa presencia en sus hogares para fomentar una educación en valores y la violencia instalada en el núcleo interno de ella, tanto y hasta la negación de la conflictividad que pueda llegar a involucrar a su hijo. Existe una escasa identificación y acompañamiento de parte de las familias al proyecto de la institución que eligen, al decidir dónde llevan a sus hijos y la falta de hábitos de convivencia que traen los niños para consigo mismos y sus compañeros, los alumnos. 
Aparece la inestabilidad y la resistencia formal a establecer vínculos sólidos entre los adultos, aumenta la agrupación de personas con menor cantidad de miembros, personas unidas por distintos lazos sanguíneos, fruto de diferentes uniones, entre otras.

En conclusión, la postmodernidad instaló una nueva cultura afectiva en las parejas, marcada por los llamados vínculos contingentes, donde la prioridad son los objetivos personales, la compañía y la contención, por encima del amor interpersonal.

En esta conflictividad se incluye el cuestionamiento y la nueva recreación de la identidad humana como elemento de construcción personal despojado de toda naturaleza determinante. El divorcio, las uniones de hecho, la desacralización del matrimonio, los nuevos conceptos de hombre y familia, el problema de la construcción de la identidad personal, son cuestiones que el docente debe atender con frecuencia en el espacio del aula para, en primer instancia, efectivizar el proceso de aprendizaje del alumno.

Incluso es motivo de alerta y atención en el aula la detección y abordaje de conflictos socio-culturales a los que se ven sometidos los niños y jóvenes en la actualidad. Violencia en el contexto familiar y maltrato infanto-juvenil, presunción de abuso sexual infantil, son algunos de los problemas que, incluso por normativa vigente, el docente debe saber cómo abordar y qué hacer frente a ello. Mencionemos brevemente de qué trata cada uno.

La "multiformidad de familias" pone a la escuela en circunstancia de cuestionamiento constante. Es evidente que a lo largo de los años ha crecido la imagen de padre "consumidor" de educación, que entiende la actividad escolar como un servicio más, lo que produce que los primeros educadores no se involucren en las trayectorias escolares de sus propios hijos.

El padre consumidor no es un padre comprometido con la educación formal de sus hijos y adopta el rol de reclamante sistemático de las "fallas en el servicio" por él elegido. Sin embargo, incluso bajo esta circunstancia, no deja de ser derecho y obligación de los padres la educación de sus hijos. A ellos atañe en primer lugar el derecho de educar, los que tienen el derecho de elegir el modo de esa formación y, por lo tanto, la clase de escuela que prefieren. Si bien 


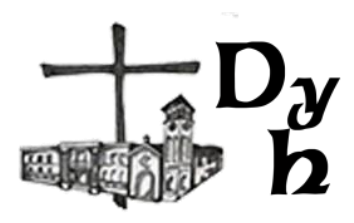

es inmediato relacionar la imagen del padre consumidor en el espectro del colegio de gestión privada, en distintos modos, también se presenta actitudinalmente en la de gestión estatal.

Como ya hemos citado, la familia atraviesa una crisis cultural profunda, como todas las comunidades y vínculos sociales. La ruptura en la transmisión generacional de la fe cristiana en el pueblo católico, responde a la falta de espacios de diálogo familiar, la influencia de los medios de comunicación, el subjetivismo relativista, el consumismo desenfrenado que alienta el mercado, la falta de acompañamiento pastoral a los más pobres, la ausencia de una acogida cordial en nuestras instituciones, y nuestra dificultad para recrear la adhesión mística de la fe en un escenario religioso plural.

El contexto social en el que debe desenvolverse tanto el alumno como la familia, determina también la intervención de los anteriores en el contacto con la escuela. El fanatismo en las opiniones, la evaluación e imposición de pensamiento y de discursos ideológico y político partidario, revolución cultural de la mente de los alumnos y profesores en general, y el consumo de sustancias psicoactivas, como el alcohol, el cigarrillo y la marihuana, son sólo algunos.

Nos encontramos transitando un contexto socio cultural en el que los principios dominantes se basan en la fascinación por mostrar conquistas sociales y políticas, o en una vanagloria ligada a la gestión de asuntos prácticos, o en un embeleso por las dinámicas de autoayuda y de realización autorreferencial.

Con el correr de los años, esto ha traído como consecuencia niveles alarmantes de odio y violencia, de la que se desprende una frecuente intolerancia hacia el otro, lo distinto, y la imposibilidad de la convivencia en la diversidad bajo normas de respeto y prosocialidad totalmente ausentes. Esto último, en el espacio del aula, demuestra a las claras las serias dificultades para la socialización entre pares y para con el docente $u$ autoridades de parte de los alumnos.

Uno de los flagelos instalados en la sociedad, que hace su gran aparición en la aulas de muy variadas formas y en distintos momentos, son las sustancias psicoactivas, entendiendo por ellas a las sustancias químicas -drogas o psicofármacos- de origen natural o sintético que afectan a las funciones del 
sistema nervioso central, es decir, al cerebro y la médula espinal. Entre sus más variados efectos podemos encontrar la inhibición del dolor, el cambio del estado de ánimo, la alteración de la percepción, entre otras. Si bien los fármacos suelen ser asociados al uso terapéutico y medicinal, las drogas suelen considerarse de uso recreativo entre los jóvenes de la actualidad.

Habitualmente, su aparición en las aulas se da en torno a los imperativos comerciales circundantes del egreso de los alumnos de los últimos años del Nivel Secundario. Sin embargo es un actor frecuente en la vida nocturna, barrial y social de los jóvenes de nuestro tiempo, ya que encuentran cierto empoderamiento sobre el grupo y la construcción de una determinada imagen personal para los demás, sometiendo su propio cuerpo a un sinfín de vejaciones, en algunos casos temporales y en otros en forma irreversible. Entre los resultados más graves vistos en el aula se encuentran las adicciones.

El momento de tomar contacto con la droga por primera vez es tan simple y, por ello, tan inocente, que la persona cree que su relación con ella siempre va a ser igual de sencilla y manejable como la de la primera vez. El alcohol se constituye en la puerta de entrada a la gran variedad de sustancias que rodean a los jóvenes que transitan hoy por nuestras escuelas.

En una primera fase, tanto el alcohol, el tabaco y la marihuana como cualquier otra droga, producen un efecto de bienestar, y se las puede consumir esporádicamente $\mathrm{o}$ en ocasiones puntuales. Una medicación durante una enfermedad, un vaso de vino acompañando la comida, son ejemplos de uso normal de una sustancia. Gradualmente y casi sin notarlo se puede pasar de la situación de uso al abuso.

La tarea del docente está atravesada por la atención continua sobre la observación de cada una de las manifestaciones conductuales del alumno en el aula; y, por consiguiente, dar los alertas correspondientes a la institución y a la familia, abrir los canales de diálogo con el joven -basando la relación en la empatía y la confianza-, y hasta, incluso, poder detectar y conocer los procedimientos y efectos de las sustancias que los alumnos están consumiendo.

Las fiestas de cada año, los encuentros inter-escolares, las previas del fin de semana, el último primer día -U.P.D.-, la noche anterior al día del número de la promoción, el último último día -U.U.D.-, el viaje de egresados, son sólo 


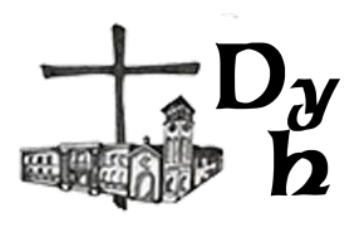

algunas de las experiencias en las que el docente se ve envuelto y en lucha permanente contra la presencia de estas sustancias y los efectos que ellas producen a nivel personal y cognitivo en los alumnos.

A su vez, se suma el abuso y la explotación de menores, el problema de las periferias y zonas empobrecidas, niños y jóvenes en situación de calle, el trabajo infantil y en situación de trata, las enfermedades físicas y mentales, en el que aparece la exacerbación de diagnósticos precoces y generalizados de los niños y jóvenes en la actualidad; son sólo algunos de los conflictos que el docente debe atender con suma prudencia y solicitud, bajo la Guía de Orientación para la Resolución de Conflictos anteriormente mencionada.

También en el aula aparecen aquellos conflictos relacionados con la atención temprana de la educación de la personalidad y las emociones de los alumnos.

Algunas de las realidades sugeridas por los docentes giran en torno a la creciente indiferencia y apatía por los temas abordados y su consecuente desmotivación en los alumnos; la imposibilidad de alcanzar un aprendizaje personalizado, producto de la excesiva cantidad de alumnos por curso, la poca tolerancia al fracaso, la habitual falta de hábitos y la nula predisposición para el estudio.

Es antiguo y corriente el dicho que "más se educa con el ejemplo que con la palabra". Parte de la tarea escolar que el docente realiza, también gira en torno a la educación emocional de los alumnos que, en la mayoría de las veces, no dominan o desconocen determinados estímulos emocionales y sentimientos, alguno de los que deberían ser creados y estimulados en el ámbito familiar, pero que aparecen ausentes.

Con frecuencia encontramos alumnos propensos al desencanto, faltos de creatividad y estímulo de la imaginación, apáticos y desinteresados por cualquier objetivo propuesto, irascibles frente a la imposibilidad de realizar algo; la frustración frente al fracaso, la falta de espacios para la reflexión e introspección; el miedo a los cambios, entre otros. Estos constituyen sólo algunas de las deficiencias emocionales de los jóvenes. 
Un estudio realizado en Estados Unidos en los años 40, que fue recientemente aplicado, demostró que los niños de hoy tienen menos capacidad para autorregular sus emociones y aguardar pacientemente. El estudio consistía en pedirles a los niños hacer una serie de ejercicios, uno de los cuales era quedarse quietos el mayor tiempo posible. Se observó que los chicos de 5 años de edad actúan como los de 3 de sesenta años atrás, en cuanto a la auto-regulación. Los de 7 años, logran aguardar sin moverse el mismo tiempo que los de 5 de seis décadas atrás. De este modo queda evidenciada la mayor energía y estimulación que tiene los niños actuales, o la dificultad para ser pacientes, independientemente de las causas de esta nueva y frecuente condición.

La imposibilidad de producir las metas esperables debido al exceso de actividades y expectativas que los niños y jóvenes cargan, sobre todo respecto de las imposiciones de sus adultos responsables y el exitismo que a ello se vincula.

El primer lugar está ocupado por lo exterior, lo inmediato, lo visible, lo rápido, lo superficial, lo provisorio; lo que produce en los alumnos indiferencia por lo que no devuelve satisfacciones inmediatas y utilitaristas, abulia frente al despliegue y estímulo de competencias desarrollables a largo plazo y disconformidad ante cualquier resultado obtenido, centrando las responsabilidades siempre en el afuera y nunca en sí mimos.

Una preocupación exacerbada por los espacios personales de autonomía y de distensión, que lleva a vivir las tareas como un mero apéndice de la vida, depositando en ellos el mero sueño de la seguridad, estabilidad y plenitud social.

Por último, y no por esto menos complejo, aparece la problemática de los usos lingüísticos, la ideología de género y la educación sexual integral.

Respecto del primer punto, lo que algunos sociólogos dieron por llamar como el "sociolecto de los jóvenes", se trata del fenómeno por el cual estos últimos se comunican, persiguiendo como objetivo el fortalecimiento de sus relaciones vivenciales próximas, sus relaciones sociales y la comunicación fáctica entre ellos. 


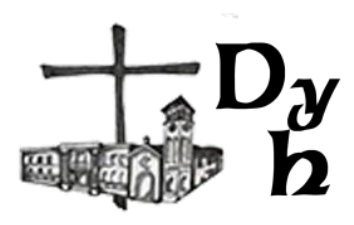

El carácter excluyente de ese sociolecto va sufriendo sistemática y velozmente modificaciones, por las que va perdiendo poco a poco su forma actual, para convertirse en nuevos usos lingüísticos validados por el grupo. Por eso, aunque el lenguaje juvenil es de corta supervivencia, su interés aumenta por el interés de la relación entre idioma y sociedad.

Por otra parte, sabemos que el proceso de aprendizaje de niños y adolescentes conlleva una lenta adaptación al lenguaje adulto. En este sentido, los rasgos distintivos del actual lenguaje juvenil se mantendrán hasta la vejez y configurarán la fisonomía del idioma en el futuro. Sin embargo, hay que aclarar que no existe un único lenguaje juvenil - la variedad de lenguajes se corresponde con las diferentes "subculturas" juveniles y sus usos connotan la pertenencia a ellas misma-, ya que se trata de un complejo fenómeno que se da en el terreno social y comunicativo provocado por diversas variables, de entre las cuales podemos concretar tres dimensiones centradas especialmente en la oralidad, la edad y la integración. A su vez, pueden aparecer factores como la metaforización, el préstamo de idiomas extranjeros, la utilización de léxico procedente del campo de la delincuencia y la droga, y el recurso del disfemismo y la grosería, es decir, de los códigos excluidos por las clases alta y media.

Este lenguaje juvenil resulta en ocasiones incomprensible y lleno de modismos. Estos usos, con frecuencia, a los docentes tienden a asombrarnos y a detener la atención en la significación que ellos revisten, porque, de ese modo, permite ver la importancia de echar luz sobre las formas de comunicación actuales de los jóvenes para poder ingresar en ese, su pequeño mundo.

Finalmente, la incorporación de la ideología de género y la educación sexual integral ha despertado en el plano educativo en general y en el aula en particular, dadas las experiencias e inquietudes de los jóvenes, grandes controversias entre docentes, alumnos, directivos, instituciones y sistema educativo oficial.

No se puede poner en duda hoy la necesidad de la educación sexual, en todas las etapas de la vida y desde un modo particular desde la niñez hasta la juventud. Ya el Concilio Vaticano II proclama la necesidad de que nuestros jóvenes sean formados en una positiva y prudente educación sexual, conforme a la edad evolutiva que transite (Pablo VI, 1965). 
Lo cuestionable, y la gran discusión actual gira en torno a qué marco teórico y bajo qué intereses fácticos es que se va a realizar esta perspectiva de la educación. Cuál será el encuadre pedagógico a utilizar, qué contenidos corresponden a cada etapa evolutiva de los destinatarios, cómo se integra este proyecto en la estructura educativa institucional, serían sólo una punta del gran iceberg.

Actualmente, los docentes que trabajamos en el sistema educativo argentino nos encontramos obligados a impartir los contenidos propuestos por la Ley 26150, sobre el Programa Nacional de Educación Sexual Integral. Esta ley fue sancionada el 4 de octubre de 2006 y promulgada el 23 del mismo mes y año.

En ella, el Poder Legislativo de la Nación Argentina sanciona con fuerza de ley el derecho de todos los educandos del país a "recibir educación sexual integral en los establecimientos educativos públicos, de gestión estatal y privada de las jurisdicciones nacional, provincial, de la Ciudad Autónoma de Buenos Aires y municipal. A los efectos de esta ley, entiéndase como educación sexual integral la que articula aspectos biológicos, psicológicos, sociales, afectivos y éticos." (Ley $N^{\circ} 26150,2006$, art. 1)

En el artículo tercero de la presente ley se establecen los objetivos que persigue, citados a continuación en forma textual:

1. propuestas educativas orientadas a la formación armónica, equilibrada y permanente de las personas;

2. asegurar la transmisión de conocimientos pertinentes, precisos, confiables y actualizados sobre los distintos aspectos involucrados en la educación sexual integral;

3. promover actitudes responsables ante la sexualidad;

4. prevenir los problemas relacionados con la salud en general y la salud sexual y reproductiva en particular;

5. procurar igualdad de trato y oportunidades para varones y mujeres. (Ley $N^{\circ} 26150,2006$, art. 3). 


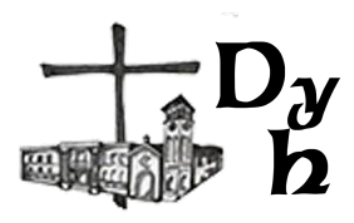

Esta ley está destinada a ser implementada por acciones concretas y lineamientos específicos -asesorados por una comisión interdisciplinaria de especialistas en la temática, convocados por el Ministerio de Educación, Ciencia y Tecnología-, desde el nivel inicial hasta el nivel superior de formación docente y de educación técnica no universitaria. Esto también obliga a las instituciones educativas a organizar espacios de formación para los padres o responsables de los menores, ya que ellos tienen el derecho a estar informados sobre la educación que se les brinda a sus hijos.

En virtud a lo establecido en la ley nacional anteriormente mencionada, el Poder Legislativo de la Provincia de Buenos Aires sanciona con fuerza ley la misma indicación bajo el número 14744, a los 4 días del mes de junio del año 2015.

Frente a esta normativa, en la Arquidiócesis de La Plata, el titular de la cátedra de por aquel entonces, S.E.R. Monseñor Héctor Aguer, emitió el decreto número 96 del 14 de septiembre de 2017, en el que reafirmó que "la Enseñanza Religiosa Escolar y la Catequesis tienen como referencia doctrinal insoslayable el Catecismo de la Iglesia Católica y el Compendio del mismo. Este decreto, del Arzobispo Emérito, se valida en la Declaración de la Comisión Episcopal de Educación Católica de la Conferencia Episcopal Argentina, del 17 de junio de 2008, que afirma que a lo largo de la elaboración de la primera ley citada, participó activamente "con sugerencias, críticas y aportes propositivos, para que el Documento final contribuyera a consolidar la formación armónica y equilibrada de la persona" (Conferencia Episcopal Argentina, 2008). Claro está que muchos de ellos no sólo no fueron incluidos en el documento final, sino que además han quedado totalmente desdibujados. $Y$, finalmente, afirma que dicha ley "concibe la identidad sexual como una construcción socio-históricocultural, relegando el hecho de que la persona humana desde su concepción biológica es sexuada, varón o mujer" (Conferencia Episcopal Argentina, 2008).

\section{El motor principal: la vocación docente}

El evangelista San Marcos narra la vocación de los primeros discípulos. "Mientras iba por la orilla del mar de Galilea, vio a Simón y a su hermano Andrés, que echaban las redes en el agua, porque eran pescadores. Jesús les 
dijo: "Síganme, y yo los haré pescadores de hombres». Inmediatamente, ellos dejaron sus redes y lo siguieron"(Mc 1, 16-20). En la convocatoria de Jesús el llamado al seguimiento consta en ir detrás de alguien, pero en este caso particular presta un sentido traslaticio, en el sentido de que seguirlo implica, en efecto, ser su discípulo. Sin embargo, en los Evangelios, no siempre aparece este término bajo el sentido que acabamos de referir. Esto demuestra que existen distintos modos por los que Jesús llama; para algunos se trata de un Ilamamiento más cercano ya que no sólo se limitan a ser testigos y heraldos de Cristo, sino que además se convierten en sus ayudantes y colaboradores en ganar a todo el pueblo para Dios.

El discipulado de Jesús se caracteriza por iniciarse en un llamado personal desde Él a sus discípulos a seguirlo; Él mismo selecciona a cada uno para formar parte de ese círculo íntimo, en el que podían figurar hombres de diversos orígenes de la sociedad. Estas exigencias tratan de discipulado entregado al amor de Dios en forma incondicional y obligatoria, como respuesta fiel a vivir la participación de la vida de Jesús. De este modo, la acción moral ejercida en la realidad común del laico católico traspasa el plano personal, ordenándola al principio de unidad que es Jesucristo.

Se trata de un ejercicio continuo y perseverante de la búsqueda de acciones que lleve a la plenitud de la vida. Cada cristiano puede tomar referencia de testimonios de vidas santas, que sirven para estimular y motivar el ejercicio de la plena libertad en las acciones morales; pero no para realizar una copia fiel de esos ejemplos, ya que ello podría alejarlo del propio camino y no dejar que brille la luz propia que Dios ha puesto en él. "Lo que interesa es que cada creyente discierna su propio camino y saque a la luz lo mejor de sí, aquello tan personal que Dios ha puesto en él (cf. 1 Co 12, 7), y no que se desgaste intentando imitar algo que no ha sido pensado para él" (Francisco, 2018, n¹1).

Pero también, si bien se conceden a la persona concreta, pueden ser participados por otros $y$, así se prolongan en el tiempo como viva y preciosa herencia, generando una afinidad espiritual particular entre las personas.

Desde una perspectiva vocacional en el marco del llamado a la santidad y ungido por el Espíritu, el cristiano aprende a comprender todas las elecciones de la existencia, incluso aquellas de carácter profesional. Es tarea de cada uno 


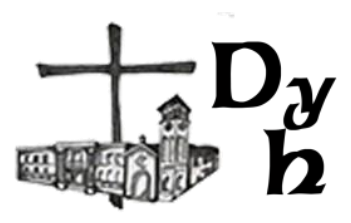

de los hombres de buena voluntad hallar las vías que contribuyan a todos y a cada uno de los cristianos a descubrir y redescubrir el vínculo entre profesión y vocación.

El docente católico se constituye como un carisma en el ámbito educativo por el que hombres y mujeres de la Iglesia desarrollan su vocación cristiana en el corazón del mundo y en el micro espacio del aula. Nuestro testimonio y actividad contribuyen a la transformación de las realidades educativas y en la creación de estructuras justas, con bases sólidas en los criterios del Evangelio de Jesucristo. Nuestro deber consta en hacer creíble, en palabras y obras, la fe que profesa en forma auténtica y coherente.

Dios nos llama y nos envía como obrero a su viña, definiendo nuestra vocación y misión personal y constituye el punto de apoyo de toda la obra formativa, ordenada al reconocimiento gozoso y agradecido de tal dignidad y al desempeño fiel y generoso de dicha responsabilidad.

Es por esto que, además de recibir la formación propia y específica al saber que debe enseñar, el docente debe incrementar su sapiencia también en lo doctrinal, pastoral y espiritual, para dar un adecuado acompañamiento de fundamentos teóricos al testimonio que brinda con sus acciones humanas en el aula. El método consta en el acercamiento fiel y perseverante a Cristo (cf. Jn. 1, 39), para poder ser partícipe de Él como el "Camino, la Verdad y la Vida" (Jn. 14, 6).

$Y$ ya que "cada santo es una misión; es un proyecto del Padre para reflejar y encarnar, en un momento determinado de la historia, un aspecto del Evangelio" (Francisco, 2018, n¹9), cada docente católico es una misión en cada aula; en el proyecto del Padre en cada escuela y en cada sistema, del momento histórico que le toque, para llevar allí la luz del Evangelio que le fue anunciado.

\section{La libertad del educador católico, el núcleo duro de la vocación docente}

El docente católico se constituye como un carisma en el ámbito educativo. Nuestro testimonio y actividad contribuye a la transformación de las realidades educativas y en la creación de estructuras justas, con bases sólidas en los criterios del Evangelio de Jesucristo, haciendo creíble, en palabras y obras, la fe que profesamos, en forma auténtica y coherente. 
La libertad cristiana es el fin que logra el hombre en general, y, este caso, el docente católico en particular, por medio de la vida con bases firmes en la verdadera moral. Ella oficia como el recurso más eficaz para alcanzar la plenitud de la libertad que le corresponde como ser racional. De hecho, así lo expresa el Catecismo de la Iglesia Católica (n. 1733):

En la medida en que el hombre hace más el bien, se va haciendo también más libre: No hay verdadera libertad sino en el servicio del bien y de la justicia. La elección de la desobediencia y del mal es un abuso de la libertad y conduce a la 'esclavitud del pecado' (cf. Rm. 6, 17).

Es decir, es libre quien puede hacer únicamente lo que quiere sin ser impedido por ninguna coacción exterior y que, por lo tanto, goza de una plena independencia de su voluntad ante una voluntad ajena. Hay que considerar que el obstáculo no siempre viene de afuera sino que también el hombre puede enfrentarse a los límites de su propia libertad, es decir, los de su propio ser.

Dado que la libertad surge del espíritu del hombre, y es allí donde se reúnen el entender y el querer, es decir, la inteligencia y la voluntad humana, el binomio verdad-libertad engrandece al hombre, lo fortalece y desarrolla la libertad individual y colectiva; en el aula, la educación hace libre al docente y educa en la libertad a los alumnos a su cargo.

Sin embargo, existen las coacciones externas que ofician de impedimento para que la voluntad del hombre, y en este caso la del docente católico, no pueda hacer uso de la plena independencia que por naturaleza lleva.

El docente católico, incluso frente a las adversidades cotidianas del aula, dejamos ver en nuestros actos morales libres el valor de la exigencia de los valores eternos y el mensaje de salvación y de vida que se esconden detrás de tamaña vocación. Nuestras convicciones son presencia testimonial de verdades difíciles y valores arduos, definido en un estilo de vida y una profesionalización ética, abierto a la comprensión de las debilidades humanas, en profunda confianza de una esperanza renovadora, percibiendo las necesidades y problemas de turno y brindando soluciones viables y encuadradas en valores nobles. 


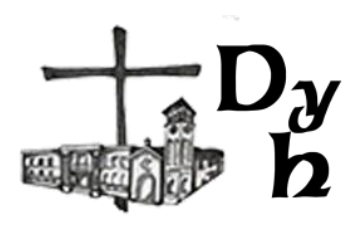

Misioneros, aun sintiéndose imperfectos. Debemos reconocer que existen diversos carismas y características; y que cada uno de ellos, a su vez, reviste diferentes modos de ser y de expresarse. Lo cual no determina la discriminación de lo propio en el común de la comunidad educativa. Es fundamental el apoyo en el sentido común personal; ser reflexivo, buscar consejo, instruirse e incrementar su sabiduría intelectual y espiritual por medio de la lectura, abandonar la egolatría profesional y abrir el espacio al aprendizaje con, por y para los demás.

Actuar con libertad en el aula no sólo implica descubrir qué y cuándo debemos hacer o no hacer algo, sino que además nos entrena en la evaluación de si hacer o no hacerlo, con qué medios debemos contar o disponer, y la sistematización con la que será abordado el acto. Frente a este procedimiento, no hay duda ni temor que amedrente o amilane. Porque conocemos de ante mano cuál es el mal que hay que evitar y el bien que hay que practicar efectivamente en cada clase, en cada aula a la que ingrese. Y lo pondrá frente a la gracia de conocer y experimentar la base de la relación personal con Dios, lo que significa que se torna plenamente libre. Profundizar nuestras acciones morales en el ambiente del aula, con mayor libertad y audacia, es el gran desafío en el ejercicio educativo y el crecimiento de nuestra vocación, promoviendo el despertar de nuevos carismas en los alumnos que educamos.

La tarea del docente católico busca, inventa, ensaya y perfecciona las posibles formas de vivir, en la propia vocación profesional, la Verdad.

\section{Nuestro Señor Jesucristo: alfa y omega, principio y fin de la educación y la libertad}

Maestro es quien ama y enseña la ardua e incesante tarea de amar, brindando el propio ejemplo personal, buscando estrategias y elaborando nuevos desafíos para lograr un posible abordaje de esa verdad.

El Maestro convoca a cada maestro a ser santo como lo es Él. Podemos reconocer en el apóstol de los gentiles la imagen ejemplificadora del discípulo humilde y fiel, el heraldo valiente y gran mediador de la Revelación. Él mismo define a los creyentes con la denominación "instruidos por Dios" (cf. 1 Tes 4, 9), es decir, que tienen a Dios por maestro; a su vez, deja en evidencia que la 
formación humana sintetiza en sí misma la educación civil y la formación religiosa. De este modo el discípulo constituirá su ser personal en una autonomía de vida libre, completa y bien preparada.

El amor del docente católico es un amor que se hace eficaz a largo plazo. La grandeza de la vocación docente se constituye en un verdadero acto de amor social. Sin embargo, la grandeza no está en la participación de la exposición pública, sino en la búsqueda del más pequeño detalle. El entrar cada día al aula, sin bajar los brazos a pesar de la variedad de dificultades, el desafío de enseñar, educar y socializar con niños y jóvenes, es un trabajo al que sólo algunos hemos sido llamados y cuya respuesta personal ha sido libre y voluntaria: "No son ustedes los que me eligieron a mí, sino yo el que los elegí a ustedes, y los destiné para que vayan y den fruto, y ese fruto sea duradero" (Jn. $15,16)$.

\section{Bibliografía}

Bergoglio, J. M. (2006). Educar: exigencia y pasión. Desafío para los educadores cristianos. Buenos Aires: Editorial Claretiana.

Conferencia Episcopal Argentina. (17 de Junio de 2008). Declaración de la Comisión Episcopal de Educación Católica de la Conferencia Episcopal Argentina ante la aprobación de los lineamientos curriculares para la Educación Sexual Integral. Obtenido de http://aica.org/aica/documentos_files/CEA/Comisiones_Episcopales/Educ acion/2008_06_17.html

Francisco, P. (2018). Gaudete et Exsultate. Exhortación Apostólica sobre el llamado a la santidad en el mundo actual. Buenos Aires: Editorial Paulinas.

Ley $N^{\circ}$ 26150. (4 de octubre de 2006). Programa Nacional de Educación Sexual Integral. Buenos Aires, Argentina.

Malaisi, L. (2016). Cómo ayudar a los niños y jóvenes de hoy. Educación Emocional. San Juan, Argentina: Editorial Educación Emocional Argentina.

Marco General de la Formación docente de Nivel Inicial y EPB de la Provincia de Buenos Aires. (2007). Dirección General de Cultura y Educación. Obtenido de 


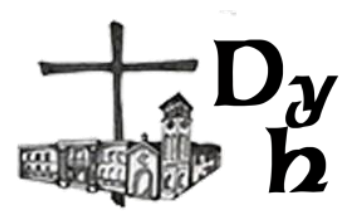

http://servicios.abc.gov.ar/lainstitucion/organismos/consejogeneral/disen ioscurriculares/documentosdescarga/dcurricularsuperior.pdf

Pablo VI, P. (1965). Gravissimum Educationis. Declaración sobre la educación cristiana. Roma: Librería Editrice Vaticana.

Sagrada Congregación para la Educación Católica. (1982). El laico católico testigo de fe en la escuela. Roma: Ediciones Paulinas.

Tenti Fanfani, E. (2004). Viejas y nuevas formas de autoridad docente. Revista Todavía $n^{\circ} 7$.

Woods, R. (2006). Vidas digitales. Buenos Aires: La Nación Revista. 